\title{
Characterization of Submicron Alumina Dispersions with Poly(methacrylic acid) Polyelectrolyte
}

\author{
Wen-Cheng J. Wei, Su Jen Lu \& Bu-Kon Yu \\ Institute of Materials Science and Engineering, National Taiwan University, Taipei, Taiwan 106
}

(Received 4 December 1993; revised version received 3 June 1994; accepted 30 June 1994)

\begin{abstract}
Colloidal dispersion of two submicron alumina powders (A-16SG and APA-0.2) and their mixtures were investigated in an aqueous suspension with and without dispersant (ammonium salt of poly(methacrylic acid), PMAAN). The (-potential and isoelectric point (iep) of the powders in aqueous solution were determined in the presence of the dispersant and electrolyte $(\mathrm{NaCl})$. The adsorption of dissociated PMAA- on alumina powders was determined via the titration technique. The dispersant was observed to exert a strong influence on the surface potential, flowing behaviors and packing densities of the aluminas. The results showed that the dispersion conditions were strongly affected by factors including the solid concentration of submicron alumina particles, the $\mathrm{pH}$ value and the concentration of PMAAN in the suspensions, and that these three factors were cross-influencing. A reaction model at the interface of alumina-solution was developed, based on the dissociation of PMAAN and the adsorption of surface hydrocarboxyl groups on alumina surface.
\end{abstract}

\section{Introduction}

Fine-grained and uniform microstructures are desirable for most structural ceramic applications in producing a strong and reliable structural part. One method which accomplishes these goals involves using submicron powder ${ }^{1-3}$ as well as processing the ceramic powder through colloidal states. ${ }^{48}$ Colloidal processing has gained considerable attention during the past decade, having proven itself as being one of the effective routes in producing high-performance ceramic components.

Ceramic particles in a solution are charged and may possibly become dispersed in a repulsive manner by the forces developed at the surface of the particles. The particles can be dispersed in an aqueous solution by three mechanisms, i.e either by electrostatic, steric, or electrosteric stabilization. ${ }^{9}$ These stabilizations are accomplished by generating common surface charges either at the surface of particles or else on the polymer chains which are adsorbed on the surface of the particle. The force, which is formed from the repulsion of similar charges and offers this stabilization, is commonly termed a Coulombic force. In addition to these forces, the adsorbed polymeric chains can also perform a spatial repulsion. Electrosteric stabilization is active if the polymer chains are absorbed on ceramic surface and the chains are charged with dissociated functional groups. It is closely related to the conformation and dissociation of polymcric chains in various acidic-basic conditions, which have been discussed extensively in consideration of the interaction with the oxide surface. ${ }^{4,5,10}$ The electrosteric effect produces significant repulsion forces between the polymeric chains and particles. However, the ceramic particles, especially for submicron powder and in high solid-content suspensions, are easily coagulated in a poor solution unless the suspension has favorable stabilization conditions.

The rheology of a ceramic suspension is strongly influenced by the nature of the ceramic particles, the composition and chemical nature of the solvent and dispersant, as well as the solid content. ${ }^{4,10,11}$ Two of the important parameters that can be used to describe the state of dispersion of ceramic colloids are the $\zeta$-potential and the isoelectric point (iep) of the colloidal surface. ${ }^{12}$ The surface potential has been extensively employed in accounting for the electrokinetics properties of ceramic suspensions. ${ }^{6,7,13}$ The values of the potential, although somewhat controlled by the nature of the solid particles, e.g. the crystalline phase ${ }^{14}$ and the surface impurity, ${ }^{15}$ are most significantly controlled by the acidity of dispersing medium and the additive (or dispersant) in the medium. 
Some research effort involving ceramic composites was recently undertaken which employs the colloidal process in preparing mixtures of various dissimilar ceramic and/or metallic colloids. The use of a toughening phase, e.g. zirconia particulates for toughening alumina, or the preparation of the mixture of two similar powders to tailor the size distribution of the powder mixture, or the production of nanocomposites would require understanding of the behavior of each phase, especially the fine portion of powder mixture, in colloidal states.

Many difficulties involving colloidal processing cases are encountered in powder mixtures. Phase segregation of ceramic particles in slip-casting, size segregation during sedimentation or consolidation of suspension, and flocculation of the fine particles in a mixture have a close relationship with the stability of a suspension system. Attempting to homogeneously mix two different powders is a rather difficult task.

Segregation of a heavy particle from the powder mixture or local segregation of different charged particles has been the major concern of these research efforts. ${ }^{6,13}$ Some useful treatments are proposed as well as some promising results being provided. Velamakanni \& Lange $^{6}$ reported that the requirements for colloidal particles to achieve their best packing properties were strong interparticle forces (high surface potential) and optimization of particle size distribution. Achieving strong interparticle forces is also true for stabilization of the suspensions with powders having different surface compositions and physical properties.

The principal objectives of this research involve analyzing the effects of polymeric dispersant when adsorbed on two alumina powders and identifying the critical parameters associated with the colloidal processes, as well as revealing the relationships of dispersion conditions with the purities of alumina powders. The phenomena of surface charging and adsorption of polymeric chains on alumina are cited here as accounting for the behavior of submicron alumina particles in a highly concentrated suspension system.

\section{Experimental procedure}

\subsection{Materials}

The alumina powders used in this study wore A16SG (supplied by Aluminum Co. of America, Pittsburg, PA, USA; BET surface area $=9.0$ $\mathrm{m}^{2} \mathrm{~g}^{-1}$, purity $=99.7 \%$ ) and APA-0.2 (supplied by Ceralox Co., Arizona, USA; BET surface area = $34.0 \mathrm{~m}^{2} \mathrm{~g}^{-1}$, purity $=99.97 \%$ ). The properties of these powders are listed in Table 1. A-16SG and
Table 1. Properties of alumina powders

\begin{tabular}{|c|c|c|}
\hline & APA $-0.2^{a}$ & $A-16 S^{b}$ \\
\hline $\operatorname{BET}\left(\mathrm{m}^{2} / \mathrm{g}\right)^{c}$ & 34 & 9 \\
\hline Particle Size, $d_{50}(\mu \mathrm{m})$ & 0.21 & 0.4 \\
\hline Phase $^{d}$ & $\theta(+\alpha)$ & $\alpha$ \\
\hline Purity $(\%)$ & $99 \cdot 97$ & $99 \cdot 7$ \\
\hline $\mathrm{Na}_{2} \mathrm{O}(\mathrm{ppm})$ & $<4$ & 800 \\
\hline $\mathrm{SiO}_{2}(\mathrm{ppm})$ & 57 & 800 \\
\hline $\mathrm{Fe}_{2} \mathrm{O}_{3}(\mathrm{ppm})$ & 126 & 100 \\
\hline $\mathrm{MgO}(\mathrm{ppm})$ & 28 & 500 \\
\hline $\mathrm{CaO}(\mathrm{ppm})$ & 2 & - \\
\hline $\mathrm{B}_{2} \mathrm{O}_{3}(\mathrm{ppm})$ & - & 10 \\
\hline Density ${ }^{e}$ & $3 \cdot 58$ & 3.986 \\
\hline
\end{tabular}

${ }^{a}$ APA-0.2 data sheet, Ceralox, Arizona, USA.

${ }^{b}$ A-16SG data sheet, Alcoa Industrial Chemicals, Pittsburgh, PA, USA.

${ }^{c}$ Nitrogen Adsorption Flowsorb 2300, Micromeritics, GA, USA.

${ }^{d}$ Verified with X-ray diffractometer, PW1729, Philips Instrument, Netherlands.

${ }^{e}$ Verified with Pycnometer 1305, Micromeritics, GA, USA.

APA-0.2 powders have a different crystalline phase and average particle size $\left(d_{50}\right)$ of 0.41 and $0.21 \mu \mathrm{m}$, respectively. A polyelectrolyte dispersant used in the preparation of dispersed alumina slurries was the ammonium salt of poly(methacrylic acid) (abbreviated as PMAAN) with molecular weight $(\mathrm{Mw})$ ranging from 10000 to 16000 . The water for dissolving dispersant was distilled, then deionized. The $\mathrm{pH}$ of alumina slurries was adjusted via the titrants diluted from analytical grade $\mathrm{HCl}$ and $\mathrm{NaOH}$. Analytical grade $\mathrm{NaCl}$ was used as an electrolyte in a concentration of $0.01 \mathrm{~N}$ to adjust the ionic strength of diluted alumina suspensions which were subjected to the measurement of $\zeta$-potential.

\subsection{Sample preparation}

\subsubsection{Slurry preparation}

The dispersant was first dissolved in the treated water. A specific amount of alumina powder was then gradually added to the solution. Some suspensions prepared for $\zeta$-potential measurement required dilution to the concentration $0.001 \mathrm{mg} \mathrm{cm}^{-3}$ for analysis. The suspension was transferred into a polyethylene (PE) bottle which was loaded with zirconia grinding media, then agitated by a turbomixer for 1-24 h. According to the volume ratio of A-16SG to APA-0.2, powder mixtures were also prepared and designated A80, A70 and A60. For instance, A80 represents an alumina (A) mixture of eight parts of A-16SG and two parts of APA- $0 \cdot 2$ by volume.

\subsubsection{Green compact preparation}

Green alumina pieces were prepared via a pressure-casting method. The alumina slurries were 
contained in an air-pressurizing mold which is constituted of two plates manufactured from 316 stainless steel and a thick-wall tube of transparent polyacrylic material. Compressed air at a pressure of $10 \mathrm{~kg} \mathrm{~cm}^{-2}$ was supplied, along with the slurry being driven through a plastic filter paper.

\subsection{Property measurement}

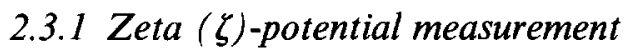

Electrophoresis measurement was conducted using a Zeta-Meter 3.0+ instrument (Zetameter Inc., USA) so as to determine the $\zeta$-potential of the alumina particles in aqueous suspension. The instrument was carefully calibrated and tested with the standard colloids offered by the manufacturer. In this study, alumina powder was dispersed in a prepared solution in a solid concentration close to $0.001 \mathrm{mg} \mathrm{cm}^{-3}$, The $\mathrm{pH}$ value of the solution with a specific amount of the dispersant was adjusted via either a dissolved acidic or a basic solution, as well as $\mathrm{NaCl}$ electrolyte. The suspension was ultrasonicated using a NEY ultrasonicator (2Q-100) at a power level of $30 \mathrm{~W}$ for at least $5 \mathrm{~min}$ before the measurement being taken.

\subsubsection{Acid titration of dispersant}

Adsorption of the dispersant on alumina powders and the $\mathrm{pH}$ of alumina suspension with various amounts of PMAAN were determined using an auto-titration instrument (VIT90 Video Titrator, TitraLab $^{\text {TM }}$ Radiometer, USA). The calibration curve of PMAAN titrated with $0.1 \mathrm{~N} \mathrm{HCl}$ is shown in the Appendix. The adsorption of PMAAN on alumina was then determined in the following procedure. The mixed alumina suspension was centrifuged using a Hermle Z380 centrifuger (Berthold Hormle GMBH \& Co, Germany) at $6000 \mathrm{rpm}$ for $60 \mathrm{~min}$ to obtain a clear suspension. The clear solution was next removed from the suspension container, and titrated with $0.1 \mathrm{~N} \mathrm{HCl}$ standard solution. The amount of required acid to balance the dissolved PMAAN in the clear suspension was determined by the IPT (infection point titration) method, which can be referred to in the operation manual of the VIT90 Video Titrator. As a consequence, $\mathrm{PMAA}^{-}$species adsorbed on alumina could be calculated from the equivalent point of the acid measured by the previously mentioned IPT method.

\subsubsection{Viscosity measurement}

The measurements were conducted with two rotary viscometers (Model DV II, Brooksfield Eng. Labs Inc., USA) which have different shear-rate ranges. These instruments were calibrated with three standard viscous fluids, which have the vis- cosities of $93.8,975$ and $12200 \mathrm{cps}$ (or mPas), respectively. Flocculation of alumina particles in a poorly dispersed slurry would influence the rheological properties of the slurry. Therefore, the measurement steps were adjusted according to previous reports; ${ }^{4,5}$ in addition, the apparent viscosity values were taken from the average of at least two different measurements.

\subsubsection{Pore size and volume measurements}

Green samples were dried at $500^{\circ} \mathrm{C}$ for $10 \mathrm{~min}$ before they were tested with a mercury porosimeter (Autopore II 9220, Micromeritics Instrument Co., USA).

\subsubsection{Microstructural observation}

Alumina green samples were broken, coated with a thin $\mathrm{Au}$ film for electric conductivity, and observed using a scanning electron microscope (JSM-T100 mini SEM, JEOL Co., Japan).

\section{Results and discussion}

\subsection{Surface potential of alumina with and without dispersant}

The effect of $\mathrm{pH}$ on the $\zeta$-potentials of the two alumina powders in an aqueous solution is shown in Fig. 1. The isoelectric point (iep) of A-16SG is at $\mathrm{pH}=8.5$, for APA- 0.2 alumina it is at $\mathrm{pH}=8.9$. According to the literature, ${ }^{11}$ the iep of aluminas could vary with the sources of alumina and the varieties of measurement techniques: The alumina prepared from the precipitation with incomplete hydration has a zero point of charge (zpc) (which could be considered as iep) near pH 6.9 if measured by the electrophoresis method. For the natural product, however, alumina has a $\mathrm{zpc}$ at $\mathrm{pH}$ 8.4 if measured by the same method, or 9.5 if by the streaming potential method. Rao ${ }^{13}$ employed two different techniques in measuring the property, reporting that the iep of alumina is at $\mathrm{pH} 9$.

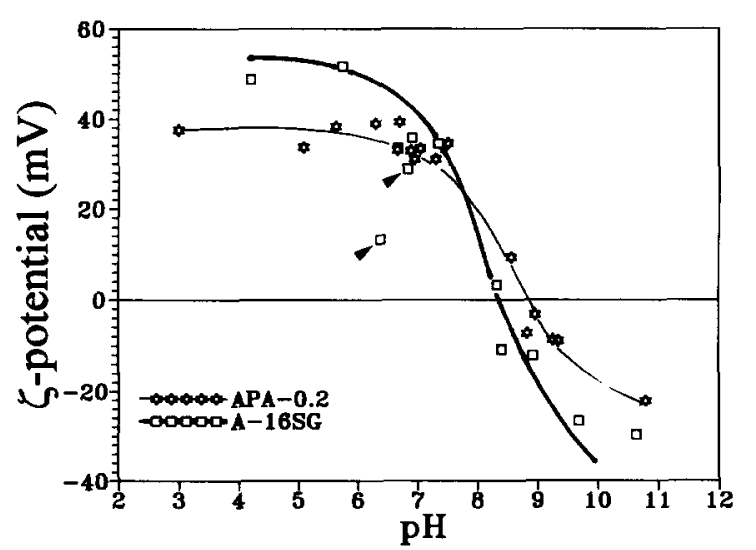

Fig. 1. Effect of $\mathrm{pH}$ on the $\zeta$-potential of A-16SG and APA0.2 alumina powders in diluted aqueous solution. The data indicated by arrows are discussed in the text. 
A similar result of the iep value of the A-16SG powder, as determined by an improved measurement apparatus, ${ }^{14}$ was reported to be at $\mathrm{pH} 8$.

Kelso \& Ferrazzolli ${ }^{15}$ determined the relative acoustophoretic mobility of A-16SG alumina in water, and found a negative mobility (i.e. a negative $\zeta$-potential on the surface) of A-16SG, as compared to a high purity alumina (XA-139SG, purity $\geq 99.95 \mathrm{wt} \%$, supplied by Alcoa, USA) which has a positive value in deionized water $(\mathrm{pH}=5 \cdot 0)$. They assumed that the surface impurity $\mathrm{Na}_{2} \mathrm{O}$ of A-16SG would possibly become ionized and for hydrated in an aqueous solution. The $\zeta$-potential of A-16SG measured in this work was a positive value, similar to that of the high purity aluminas, XA-139SG, ${ }^{14}$ and APA-0.2 in the present case. However, the surface potential values of A-16SG were observed in this study to be rather dependent upon the aging time of the alumina suspension. The $\zeta$-potential values of $\mathrm{A}-16 \mathrm{SG}$ are relatively scattered within the range $\mathrm{pH} 5-7$, and would be smaller in value if the suspension is aged more than $30 \mathrm{~min}$, as shown by two data points in Fig. 1. It is due to the release of ionizable species, e.g. $\mathrm{Na}^{+}, \mathrm{Mg}^{+2}$, from the powder. High purity APA0.2 powder has a consistent surface charge in an aqueous solution.

At the $\mathrm{pH}$ below the iep of alumina, the aqueous solution permits charge and proton transfer at the solid-solution interface, resulting in an electrically positive surface on alumina, e.g. the formation of $\mathrm{AlOH}_{2}{ }^{+}$. That is the reason why the alumina particles in weakly acidic water solution exhibits a positive potential. However, the observation of the $\mathrm{pH}$ value of freshly prepared suspensions changed from weakly acidic to neutral, or to weakly basic conditions as they aged. A similar change was reported ${ }^{15}$ in which the $\mathrm{pH}$ of the water increased up to 9.6 for an alumina content in the solution of $16.7 \mathrm{wt} \%$. The acidity of the suspension is dependent on the interaction of alumina in acidic suspension. However, the formation of the positive $\mathrm{AlOH}_{2}{ }^{+}$species is interrupted by the presence of $\mathrm{Na}_{2} \mathrm{O}$ and other ionizable oxide impurities. Surface $\mathrm{Na}_{2} \mathrm{O}$ is considered here as possibly releasing $\mathrm{Na}^{+}$in forming a negative $\mathrm{NaO}^{-}$so as to compensate for the positive charge $\left(\mathrm{AlOH}_{2}{ }^{+}\right)$on the surface of alumina. In addition, $\mathrm{MgO}$, used as a grain-growth inhibitor, (as is the report indicated in by the powder supplier, Alcoa, USA), is present in A-16SG, and tends to dissolve in water to form a strongly basic solution. The contents of $\mathrm{Na}_{2} \mathrm{O}$ and $\mathrm{MgO}$ are appreciable ( $0.08 \%$ and $0.05 \%$, respectively) in A-16SG, but ignorable in a high purity APA- $0 \cdot 2$ powder (Table 1). Therefore, the dissolution of $\mathrm{Na}_{2} \mathrm{O}$ and $\mathrm{MgO}$ is not occurring in APA- 0.2 between pH 5 to 7 in

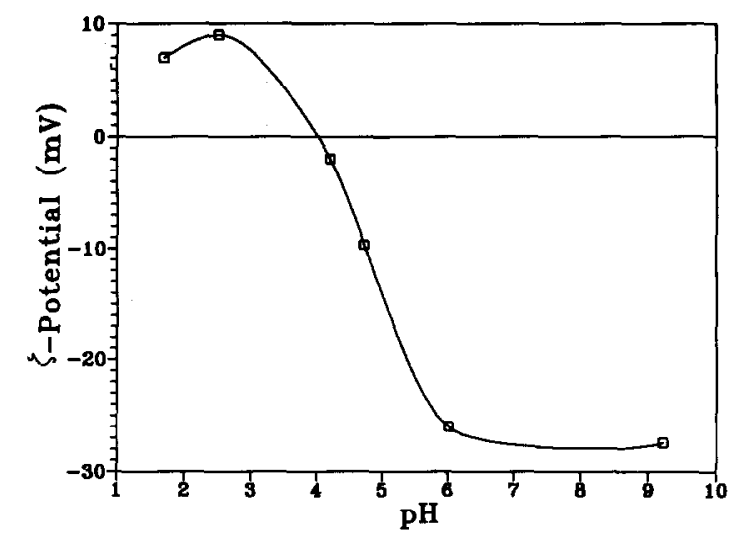

Fig. 2. Effect of $\mathrm{pH}$ on the $\zeta$-potential of diluted A-16SG slurries with $0 \cdot 125 \mathrm{wt} \%$ PMAAN (based on alumina).

Fig. 1. The dissolved $\mathrm{Na}$ and $\mathrm{Mg}$ ions could alter the thickness of the double layer on the surface of alumina particles. As a consequence, the $\zeta$-potential of A-16SG at the $\mathrm{pH}$ away from its iep is higher than that of APA- 0.2 particles. The significance of surfacc impurities having reacted with water shows that the surface potential can be a time-dependent variable.

Figure 2 shows the effect of $\mathrm{pH}$ on the $\zeta$-potential of diluted A-16SG suspensions originally containing $30 \mathrm{wt} \%$ alumina and $0.125 \mathrm{wt} \%$ PMAAN (based on alumina). The alumina surface has reversed its electrical charging condition at $\mathrm{pH}$ 4.0. A similar chemical PMAA-Na salt ${ }^{4}$ was reported as not being dissociated at the $\mathrm{pH}$ below $3 \cdot 5$, but fully dissociated at the $\mathrm{pH}$ values over than 8.0 . If the dispersant used in this study has a similar dissociation behavior, the adsorption of dissociated PMAA $^{-}$can only take place at the $\mathrm{pH}$ ranging from 3.5 to 8.2 (the iep of A-16SG). The surface potential of the alumina, which is positively changed, shifts to negative when the surface is covered with $\mathrm{PMAA}^{-}$. As a result, the $\zeta$-potential in the acidic conditions $(\mathrm{pH}=3 \cdot 5-8 \cdot 2)$ is changed from a positive to a negative surface. Thus, iep of A-16SG in the presence of PMAAN is accordingly changed to $\mathrm{pH} 4.0$.

A plot of the $\zeta$-potential of A-16SG and APA0.2 suspensions is provided in Fig. 3 which contains $0.01 \mathrm{~N}$ electrolyte $\mathrm{NaCl}$ and various amount of PMAAN. The surface potential of A-16SG alumina in diluted $\mathrm{NaCl}(0.01 \mathrm{~N})$ solution is about 38 $\mathrm{mV}$. However, the potential dramatically changes to negative if the amount of PMAAN is more than $0.02 \mathrm{wt} \%$ based on A-16SG alumina. Similarly the potential of APA- 0.2 reverses as the concentration of PMAAN is greater than $0.04 \mathrm{wt} \%$. That is a result of adsorption of a dispersant with an anionic-type functional group, and the amount of dispersant is surface-area dependent. The potential values, which reach a plateau, show that the adsorption on alumina becomes saturated if 


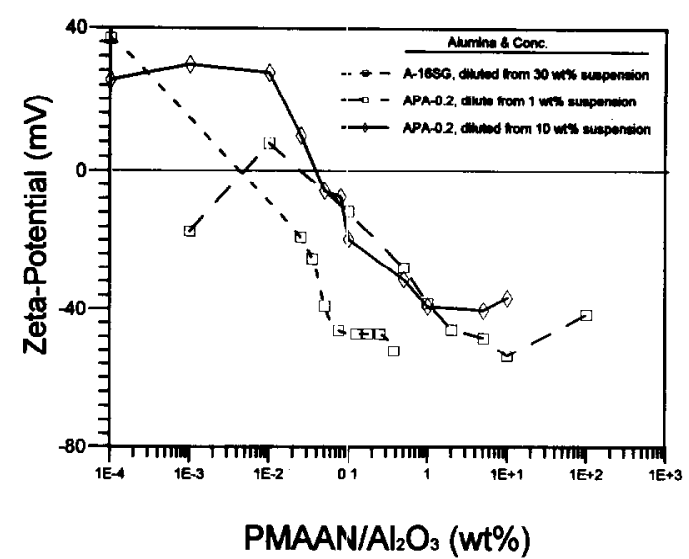

Fig. 3. Effect of PMAAN on the $\zeta$-potential of A-16SG and APA-0.2 slurries which contain $0.01 \mathrm{~N} \mathrm{NaCl}$.

more than $0.07 \mathrm{wt} \%$ or $0.5 \mathrm{wt} \%$ PMAAN is added in the A-16SG or APA- 0.2 suspensions, respectively.

The $\mathrm{pH}$ values of suspensions which contain various amounts of alunina are plotted in Fig. 4 against the added PMAAN. These results show that the water changes its $\mathrm{pH}$ value to weakly basic ( $\mathrm{pH} \mathrm{8.0)}$ ) if PMAAN is added - even as little as $0.01 \mathrm{wt} \%$ (based on the solution). However, the $\mathrm{pH}$ becomes more basic if A-16SG powder is added at a level of more than $1.0 \mathrm{wt} \%$ of the deionized water. Kelso \& Ferrazzolli ${ }^{15}$ reported a similar change of the $\mathrm{pH}$ of pure water up to 9.6 if the addition of $\mathrm{A}-16 \mathrm{SG}$ alumina powder in the solution was $16.7 \mathrm{wt} \%$, but up to $\mathrm{pH} 8.0$ if the solution contained the same amount of highpurity alumina (XA-139\$G).

First of all, the alumira surface tends to change from a neutral surface to a positively charged surface as alumina powder is steeped in deionized water. The adsorption of protons on the alumina surface causes the water to have an increasing $\mathrm{OH}^{-}$concentration. This concentration causes the $\mathrm{pH}$ of the solution to be basic $(\mathrm{pH}>7)$. The newly formed aluminum hydrate has an amphoteric property. The reactions of the hydrated alumina surface at varicus $\mathrm{pH}$ conditions can be expressed as follows

$$
\begin{aligned}
& x \mathrm{H}_{3} \mathrm{O}^{+}+[\mathrm{O}-\mathrm{Al}-]_{n}(\mathrm{OH})_{x} \\
& \quad \Leftrightarrow[\mathrm{O}-\mathrm{Al}-]_{n}\left(\mathrm{OH}_{2}^{+}\right)_{x}+x \mathrm{H}_{2} \mathrm{O} \text { at } \mathrm{pH} \leq \text { iep } \\
& {[\mathrm{O}-\mathrm{Al}-]_{n}(\mathrm{OH})_{x}+x \mathrm{OH}^{-}} \\
& \quad \Leftrightarrow x \mathrm{H}_{2} \mathrm{O}+[\mathrm{O}-\mathrm{Al}-]_{n}\left(\mathrm{O}^{-}\right)_{x} \quad \text { at } \mathrm{pH} \geq \text { iep }
\end{aligned}
$$

However, the dissolution of PMAAN in water would interfere with the $\mathrm{pH}$ value of the suspension. The alumina suspension $\left(\mathrm{Al}_{2} \mathrm{O}_{3}\right.$ content $\geq 1 \cdot 0$ $\mathrm{wt} \%$ of the solution) is indicated from Fig. 4(a) to have higher $\mathrm{pH}$ values than the aqueous solution only with PMAAN. The difference of the $\mathrm{pH}$ value between the solution (with PMAAN) and alumina suspension is reducing (approaching to

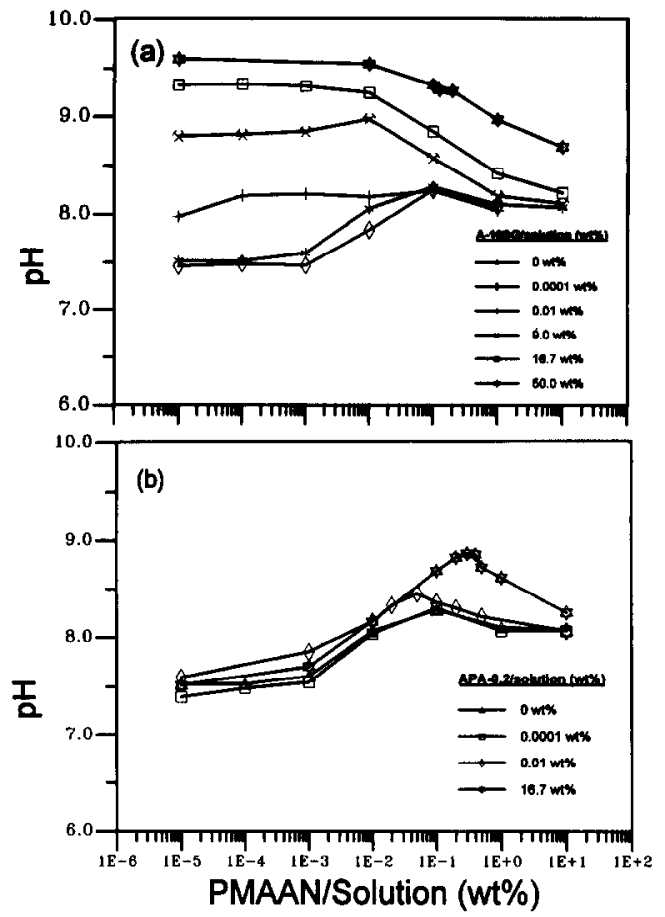

Fig. 4. Effect of PMAAN on the pH of alumina slurries for various concentrations of alumina (a) A-16SG and (b) APA-0.2.

$\mathrm{pH} 8 \cdot 3$ ) as the PMAAN concentration increases. The presence of alumina and PMAAN chemical have closely interfered with each other in aqueous solution.

Alumina is scarcely dissolved in a weakly basic solution of which the added PMAAN gives a stable $\mathrm{pH}$ value near $8 \cdot 1$. For a suspension system including a solid phase in equilibrium with the solution, the isoelectric point of the solution corresponds to the point of minimum solubility of the solid. ${ }^{12}$ The formation of molecular $\mathrm{Al}(\mathrm{OH})_{3}$ or $\mathrm{AlOOH}$ in weakly basic alumina suspension is ignorable. For the reactions of PMAAN, a combination of the dissociation of PMAAN and the adsorption of PMAA $^{-}$on the alumina surface, are revealed by the $\mathrm{pH}$ evaluation of alumina suspensions.

The dissociation of PMAAN and the reaction with water can be expressed in the following equations:

$$
\begin{aligned}
& \text { PMAA }-\mathrm{NH}_{4} \Leftrightarrow \mathrm{PMAA}^{-}+\mathrm{NH}_{4}^{+} \\
& \mathrm{PMAA}^{-}+\mathrm{H}_{2} \mathrm{O} \Leftrightarrow \mathrm{PMAA}-\mathrm{H}+\mathrm{OH}^{-}
\end{aligned}
$$

If $\alpha$ is the fraction of dissociated group of PMAAN in suspension. The titration of a 33 vol. $\%$ (or $66 \mathrm{wt} \%$ ) A-16SG suspension with 0.125 $\mathrm{wt}^{\mathrm{O}} \%$ PMAAN reveals that nearly $32 \%$ of PMAA $^{-}$ is adsorbed on the surface of APA-0.2. A high concentration (about 2/3) of the charged polymeric chains of $\mathrm{PMAA}^{-}$is available in this suspension and can be adsorbed on alumina particles, subsequently resulting in the decrease of surface potential (Fig. 3) of the alumina. However, several 


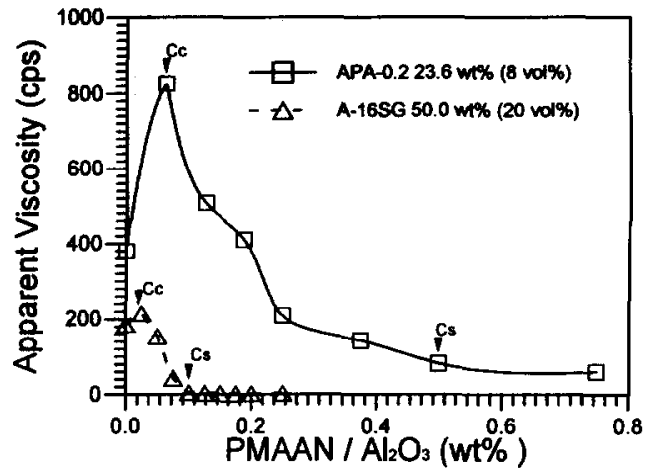

Fig. 5. Effect of PMAAN on the apparent viscosity of A-16SG and APA-0.2 slurries tested in a shear rate $18 \mathrm{~s}^{-1}$.

researchers ${ }^{4,10}$ have pointed out that the conformation of $\mathrm{PMAA}^{-}$or a similar polymer, e.g. PAA $^{-}$, in weak base, influenced its adsorption phenomena near the saturation point. The stretched $\mathrm{PMAA}^{-}$prevents more $\mathrm{PMAA}^{-}$from adsorbing at the alumina particle surface. Therefore, the $\zeta$-potential of A-16SG and APA-0.2 alumina suspensions can no longer increase their absolute values.

The adsorption of dissociated PMAAN on alumina not only alters the surface potential of alumina, but also changes the $\mathrm{pH}$ value of the solution if the adsorption on alumina is over the saturation point. As the concentration of PMAAN in A-16SG suspension rises over $0.01 \mathrm{wt} \%$, the $\mathrm{pH}$ (or the acidity) of the alumina suspension changes to close to the $\mathrm{pH}$ of pure PMAAN with aqueous solution, but for high purity APA- $0 \cdot 2$ it is over $0.05 \mathrm{wt} \%$, as revealed in Fig. 4(a) and (b). Therefore, the $\mathrm{pH}$ of alumina suspension with an increase of non-adsorbed PMAAN approaches 8.1.

\subsection{Slurry viscosity}

The addition of dispersant PMAA- $\mathrm{NH}_{4}$ can effectively reduce the viscosity of the alumina slurries if it is added into the formulation in a concentration of more than a critical amount $\left(C_{\mathrm{c}}\right) . C_{\mathrm{c}}$ is $0.02 \mathrm{wt} \%$ for A-16SG and $0.07 \mathrm{wt} \%$ for APA- 0.2 , as illustrated in Fig. 5. the electrosteric repulsion which arises from the adsorption of $\mathrm{PMAA}^{-}$ polymeric chains on alumina is effective only if the added PMAAN is in an amount over $C_{\mathrm{c}}$. This observation is consistent with the reverse of surface potential observed in Fig. 3. The interparticle forces, which are a result of surface electric potential, stabilize the colloidal particles in the concentrated suspension. Since the adsorption of the $\mathrm{PMAA}^{-}$on the alumina is near the saturation point ( $C_{\mathrm{s}}$ in Fig. 5), the surface potential of A$16 \mathrm{SG}$ alumina is maintained at around $47 \mathrm{mV}$ (Fig. 3), which is nearly the maximum potential in the suspension. A strong surface potential causes the viscosity of the A-16SG suspension to reach

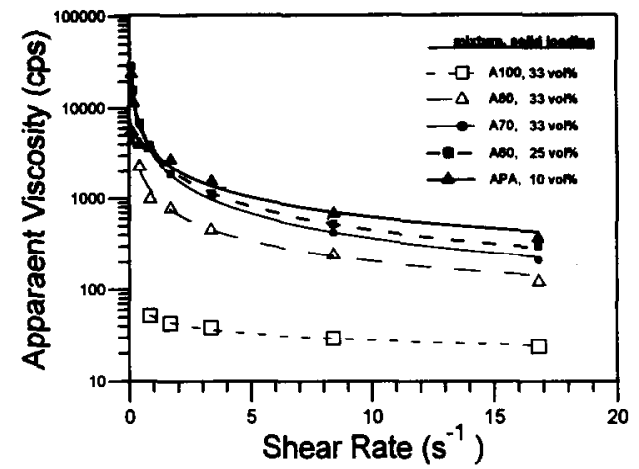

Fig. 6. Apparent viscosity of various alumina slurries with $0.5 \mathrm{wt} \%$ PMAAN (based on alumina) at various shear rates.

its lowest value. Similar behavior is found for the APA- $0 \cdot 2$ suspension containing a lower solid content (i.e. 8 vol.\%) than the A-16SG suspension.

The amount of polyelectrolyte necessary to achieve a good dispersion is surface-area dependent. The BET surface area of APA-0.2 is about four times higher than that of A-16SG powder, as indicated from Table 1. The curves provided in Fig. 5 are similar, only different in the scale of viscosity. The ratio of the critical amount $\left(C_{\mathrm{c}}\right)$ and the saturation amount $\left(C_{\mathrm{s}}\right)$ of required PMAAN implies that the specific surface area of the two powders, one of $34 \mathrm{~m}^{2} \mathrm{~g}^{-1}$ the other of $9 \mathrm{~m}^{2} \mathrm{~g}^{-1}$, is dominating the required amount of adsorbed PMAA $^{-}$

Figure 6 illustrates the effect of PMAAN on the apparent viscosity of pure A-16SG, APA-0.2 slurries and the slurries of their mixtures, A80, A70 and A60. The rheological data in Fig. 6 were measured from the slurries with various solid concentrations. One APA- $0 \cdot 2$ suspension can only be dispersed at the solid concentration less than 15 vol. $\%$. All of the APA- 0.2 containing slurries have a pseudo-plastic flow behavior; however, pure A16SG slurry is nearly Newtonian. It has been demonstrated $^{16}$ by the Dougherty-Krieger equation that the rheological states are mainly affected by the solid loading (or solid/liquid ratio), particle shape and the average particle size. Interactions between the electrical double layer and/or the adsorbed polyelectrolyte have to be taken into account, ${ }^{17}$ if the volume fraction of the particles in suspension is increased. The suspension of APA$0 \cdot 2$, having an average particle size two times less than that of A-16SG, was confirmed in this study as being very viscous (almost gelled) at solid concentrations over $15 \mathrm{vol} . \%$ if only $0.5 \mathrm{wt} \%$ PMAAN dispersant was used.

$\mathrm{RaO}^{13}$ has reported that the electrophoretic mobility versus $\mathrm{pH}$ profiles and the position of the isoelectric point of powder mixtures are apparently governed by the powder having a large total surface area in the mixture, but not necessarily the 


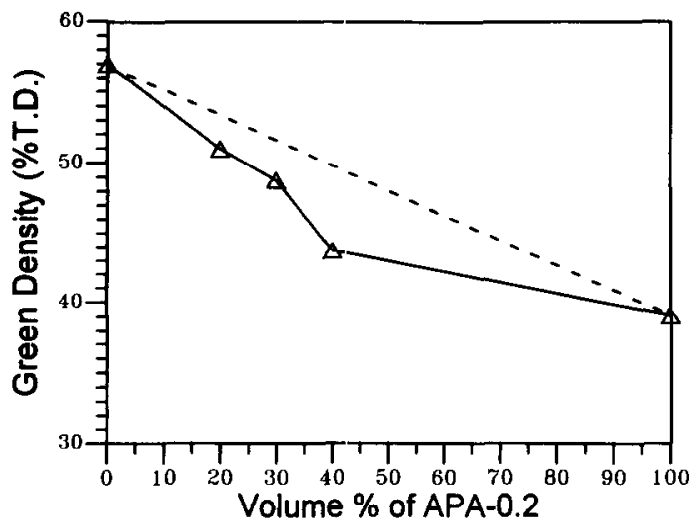

Fig. 7. Green densities of various alumina mixtures. weight fraction. Thus, the viscosity of the mixed suspension could be controlled by the flowing behavior of fine APA-0.2 powder, as depicted in Fig. 6.

\subsection{Properties of green alumina mixtures}

Green densities of various alumina mixtures, which have been pressure-casted and dried, are given in Fig. 7. The green density is an index of powder packing conditions. A-16SG has a relative green density of 0.57, APA- 0.2 is 0.39 only. The green pieces were prepared from the slurries with 0.125
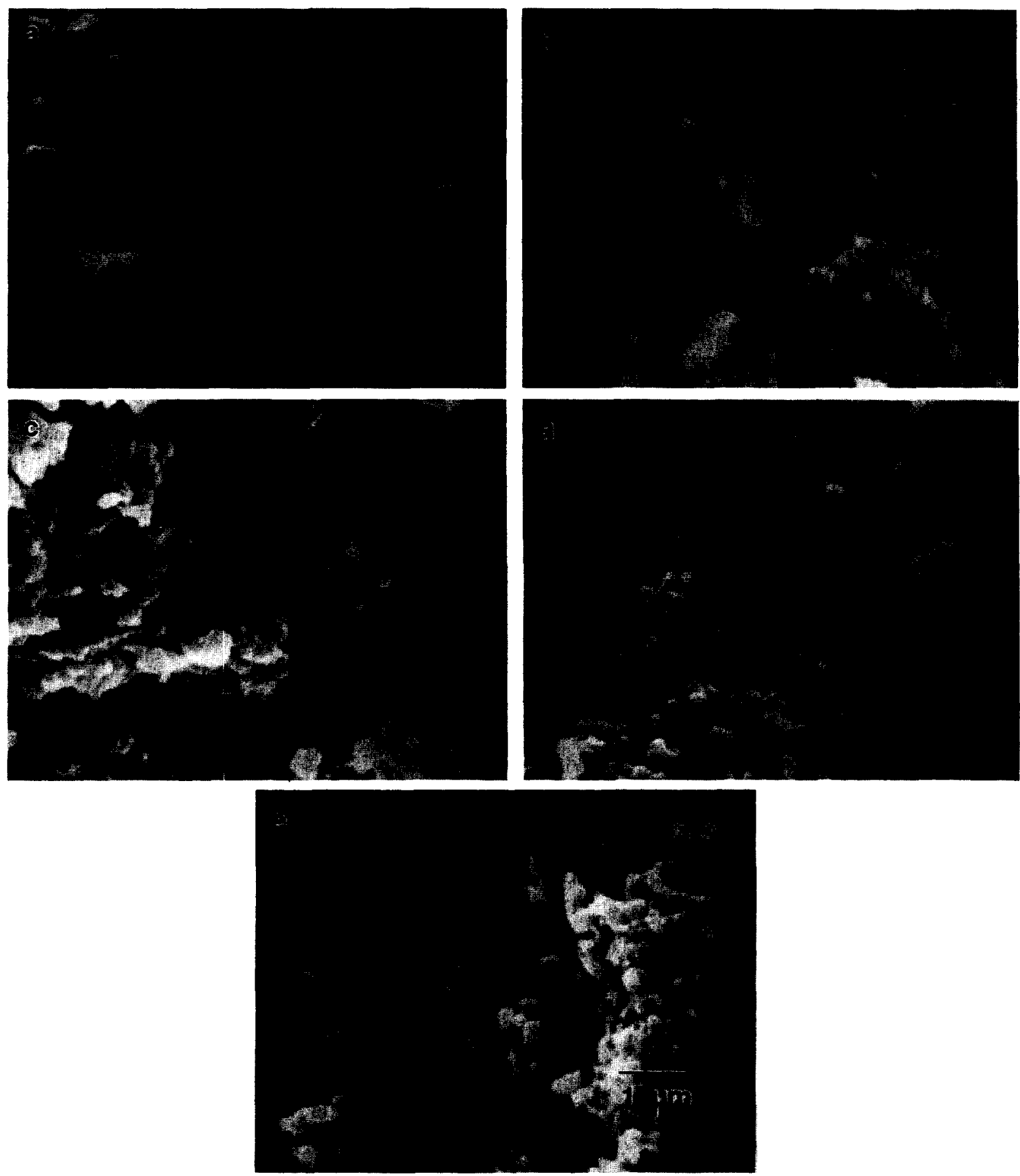

Fig. 8. SEM micrographs of the fracture surfaces of green (a) A-16SG, (b) APA-0.2, (c) A80, (d) A70 and (e) A60 powder compacts. 
or $0.5 \mathrm{wt} \%$ PMAAN dispersant (based on alumina). The difference of green densities between two green pure materials is mainly a result of the surface forces and the dispersion conditions of powders. The slurries of the fine agglomerated APA- 0.2 particles still produce the green pieces in a loose pack.

Zok et al. ${ }^{19}$ developed a model of binary powder packing to illustrate the effects of large particle surface and touching of the particles on the packing density of ceramic powders. In contrast, Messing \& Onoda's work ${ }^{20}$ attempted to describe the inhomogeneity (defined by the degree of mixing) on the packing density of binary powder. Both groups pointed out that the experimental data for composite mixtures deviate from the theoretical values of ideal packing density. Particularly, packing densities of different size powder mixtures are higher than random packing densities of the mixtures. In Velamakanni \& Lange's work, ${ }^{6}$ the fine alumina, AKP-series, has a random packing density of 0.63 , however the mixtures with 20 to $40 \%$ fines allow a density of 0.68 to be reached, which is far lower than the theoretical density 0.87 , but those values are still larger than 0.63.

In the present case, the green densities of the mixtures (A80, A70 and A60) are even lower than those density values calculated from the volume fractions of two-ended materials, as the broken line indicates in Fig. 7. Restated, the powder mixtures have shear thickening properties. The reasons for a reduction of the packing density have been proposed by others ${ }^{6}$ as possibly being physically a consequence of the presence of local compositional variations. In the present case, the composition variation should be treated as a packing-type structural variation in the mixtures of two alumina powders. The observation (Fig. $8(c)$ to (e)) of the fractured surfaces of three mixtures has confirmed that fine alumina particles (APA-0.2) are retaining some degree of agglomeration in sizes $0.6 \mu \mathrm{m}$ or larger. The agglomerates are still retained from previous dispersion and mixing stages. Therefore, the green powder mixtures have at least two varieties of porosity. The porosity was revealed by the measurement of pore size, and the results were plotted in Fig. 9. The pore size distribution of APA- 0.2 has two maxima, i.e. at 0.09 and $0.035 \mu \mathrm{m}$, respectively. The fine pores, which are believed to have formed between agglomerates, are one of the characteristics of partially agglomerated powder. Additionally, the pore size distributions of A80, A70 and A60 notably exhibits a fraction of pores having sizes ranging from 0.02 to $0.06 \mu \mathrm{m}$ (Fig. 9(a)) similar to that of APA- $0 \cdot 2$. The mixtures possess some degree of the agglomeration of pure APA- 0.2 powder.
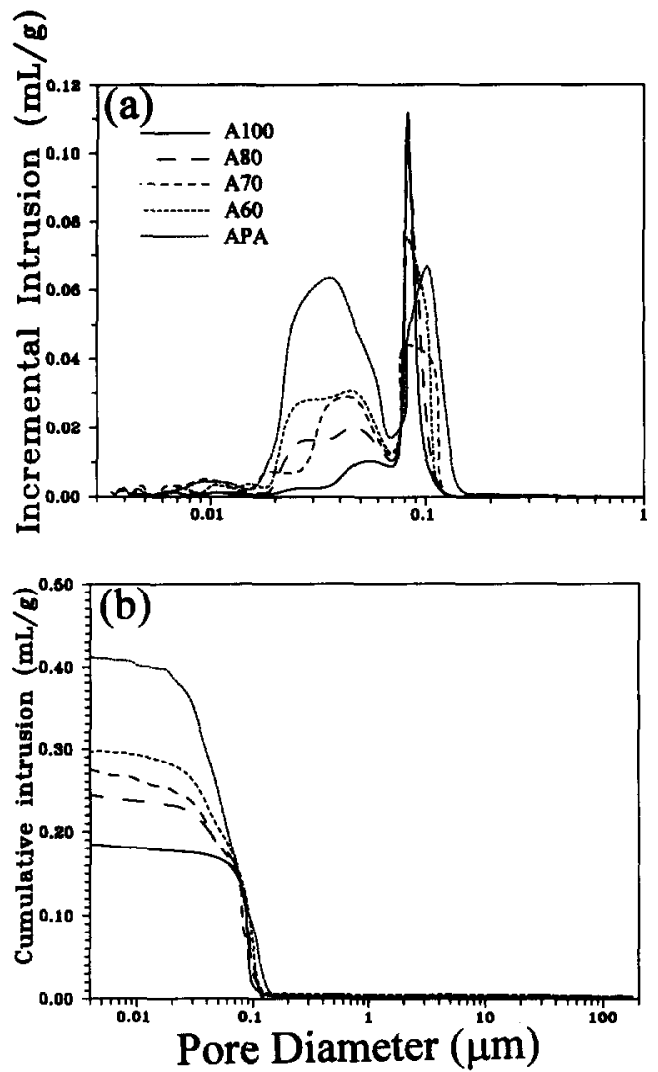

Fig. 9. (a) Pore size distribution and (b) cumulative pore volume of various alumina mixtures.

\section{Conclusion}

The surface potential, adsorption of dispersant, flowing behavior and green packing properties of alumina powders in additional of PMAAN dispersant were investigated in this study. The packing and mixing of ideal powder mixtures could be optimized not only from the dispersing conditions, but most importantly from the control of agglomeration-especially in fine powder. Some conclusions can be drawn, i.e.:

(1) The iep of A-16SG powder in aqueous suspension is determined to be at $\mathrm{pH}=8.5$ and that of APA- 0.2 is at $\mathrm{pH}=8.9$. The iep is shifted to $\mathrm{pH} 4.0$ if the anionic-type dispersant PMAAN is added to the alumina suspension;

(2) The adsorption of dispersant PMAAN changes the surface potential of A-16SG and APA- 0.2 to negative values and also offers an electrosteric stabilization for alumina particles in aqueous solution;

(3) The rheological behavior of pure alumina particles in suspension is controlled by the reactions of PMAAN, the specific surface area of the powder, acidity and solid loading of the suspension. Conversely, the dissociation of PMAAN is affected by the amount of alumina powder in suspension; 
(4) The flowing behavior of the alumina suspension which is the mixture of two powders is dominated by the fine powder, i.e. APA- $0 \cdot 2$, which is still partially agglomerated in dispersed suspension; and

(5) APA- 0.2 is difficult to fully disperse in an aqueous condition. Its green compacts exhibit a bimodal distribution porosity with pore sizes around 0.09 and $0.035 \mu \mathrm{m}$. The fine pores are retained in powder mixtures which are similar to that of pure APA-0.2.

\section{Acknowledgment}

The authors would like to acknowledge the funding from National Science Council (\#NSC820405-E002-119) and thank Professor Dah-Tong Ray for the measurement of $\zeta$-potential conducted in his laboratory at the National Cheng-Kung University. Helpful discussion with Professors D. S. Tsai and K. S. Chou is also acknowledged.

\section{References}

1. Yeh, T.-S. \& Sacks, M. D., Low temperature sintering of aluminum oxide, J. Am. Ceram., 71(10) (1988) 841-4.

2. Yeh, T.-S. \& Sacks, M. D., Effect of particle size distribution on the sintering of alumina. Comm. Am. Ceram. Soc., 71(12) (1988) C-484-C-487.

3. Tsai, D.-S. \& Hsieh, C.-C., Controlled gelation and sintering of monolithic gels prepared from $\gamma$-alumina fume powder. J. Am. Ceram. Soc., 74(4) (1991) 830-6.

4. Cesarano III, J., Aksay, I. A. \& Bleier, A., Stability of aqueous $\alpha$-alumina suspensions with poly(methacrylic acid) polyelectrolyte. J. Am. Ceram. Soc., 71(4) (1988) 250-5.

5. Cesarano III, J. \& Aksay, I. A., Processing of highly concentrated aqueous $\alpha$-alumina suspensions stabilised with polyelectrolytes. J. Am. Ceram. Soc., 71(12) (1988) 1062-7.
6. Velamakanni, B. V. \& Lange, F. F., Effect of interparticle potentials and sedimentation on particle packing density of bimodal particle distributions during pressure filtration. J. Am. Ceram. Soc., 74(1) (1991) 166-72.

7. Hirata, Y., Nishimoto, A. \& Ishihara, Y., Effects of addition of polyacrylic ammonium on colloidal processing of $\alpha$-alumina. J. Ceram. Soc. Jpn, Int. Edn, 100 (1992) 972.

8. Novich, B. E. \& Pyatt, D. H., Consolidation behavior of high-performance ceramic suspension. J. Am. Ceram. Soc., 73(2) (1990) 207-12.

9. Napper, D. H., Polymeric Stabilization of Colloidal Dispersions. Academic Press, London, 1983, pp. 8-15.

10. Chen Z. C., Ring, T. A. \& Lemaitre, J., Stabilization and processing of aqueous $\mathrm{BaTiO}_{3}$ suspension with polyacrylic acid. J. Am. Ceram. Soc., 75(12) (1992) 3201-8.

11. Chou, K. S. \& Lee, L. J., Effect of dispersants on the rheological properties and slip casting of concentrated alumina slurry. J. Am. Ceram. Soc., 72(9) (1989) 1622-7.

12. Parks, G. A., The isoelectric points of solid oxides, solid hydroxides and aqueous hydroxy complex systems. Chem. Rev., 65 (1965) 177.

13. Rao, A. S., Electrophoretic mobility of alumina, titania and their mixtures in aqueous dispersion. Ceram. Int., 14 (1988) 71-6.

14. Hashiba, M., Okamoto, H., Nurishi, Y. \& Hiramatsu, $\mathrm{K}$., The zeta-potential measurement for concentrated aqueous suspension by improved electrophoretic mass transport apparatus-application to $\mathrm{Al}_{2} \mathrm{O}_{3}, \mathrm{ZrO}_{2}$ and $\mathrm{SiC}$ suspension. J. Mat. Sci., 23 (1988) 2893-6.

15. Kelso, J. F. \& Ferrazzoli, T. A., Effect of powder surface chemistry on the stability of concentrated aqueous dispersions of alumina. J. Am. Ceram. Soc., 72(4) (1989) 625-7.

16. Lee, Y. C. \& Wei, W., Dispersion and high-pressure filtration of zircon/alumina composite slurry. Chin. J. Mat. Sci., 24(2) (1992) 113-22.

17. Frith, W. J., Mewis, J. \& Strivens, T. A., Rheology of concentrated suspensions: experimental investigations. Powder Tech., 51 (1987) 27-34.

18. Nikumbh, A. K., Schmidt, H., Martin, K., Porz, F. \& Thummler, F., Influence of $\mathrm{pH}$ on rheological properties of alumina slips. J. Mat. Sci., 25 (1990) 15-21.

19. Zok, F., Lange, F. F. \& Porter, J. R., Packing density of composite powder mixtures. J. Am. Ceram. Soc., 74(8) (1991) 1880-5.

20. Messing, G. L. \& Onoda, G. Y., Inhomogeneity-packing density relations in binary powders-experimental studies. J. Am. Ceram. Soc., 61(7-8) (1978) 363-6. 
Appendix

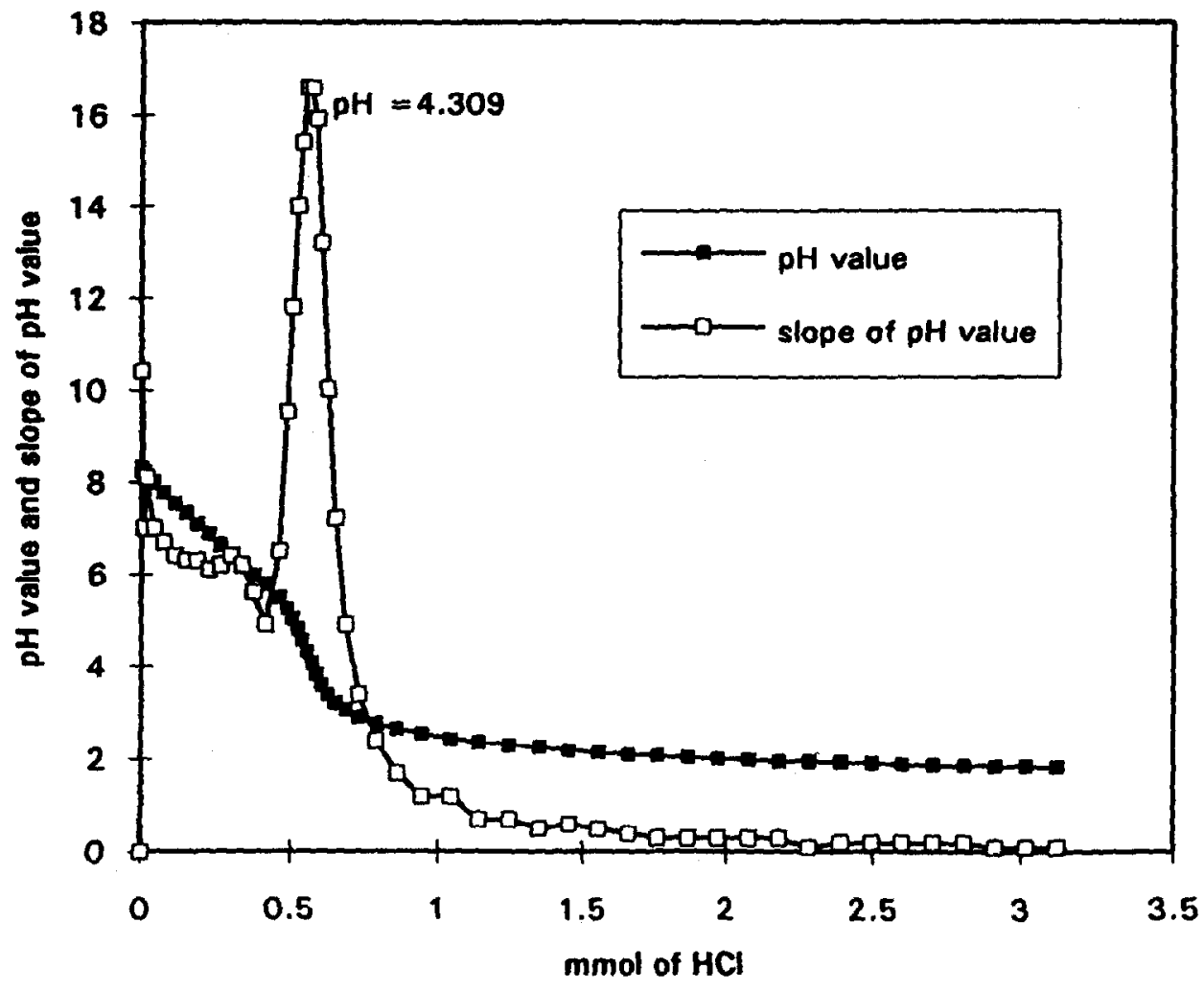

Fig. A1. The titration curve of PMAAN by $0.1 \mathrm{~N} \mathrm{HCl}$ standard acid. The equivalent point of $0.25 \mathrm{~g}$ PMAAN is determined to be $0.268 \mathrm{mmol}$ of $\mathrm{HCl}$ at $\mathrm{pH} 4.3$. 